\title{
Exophytic Uterine Leiomyoma
}

Angela Sehra, Seema Bhardwaj, Shewta, Anandita

Department of Obstetrics and Gynaecology, Maharaja Agrasen Hospital, New Delhi, India.

\section{Abstract:}

Uterine fibroids are fairly common entity, but it is rare to find a subserous fibroid with a pedicle (stalk). As these fibroid grow larger they can become twisted, resulting in severe pain. They get separated from the uterus and are mistaken for adnexal mass. Diagnosis of pedunculated leiomyoma can be established by ultrasound which shows palpable mass separate from uterus and ovaries. They become parasitic after developing auxiliary blood supply. In elective cases, diagnostic laparoscopic examination before laparotomy can be useful.

Key words: Laparatomy, Leiomyoma, Ovary, Pain, Uterus.

\section{Introduction}

Leiomyomas are the most common benign uterine tumors. They may be intramural, subserosal, or submucosal in location. Subserosal leiomyomas may be beneath the uterine surface, exophytic or pedunculated. Submucosal leiomyomas may protrude into the uterine cavity and may also become pedunculated. If pedunculated subserosal leiomyoma develops an extremely long tenuous stalk, it is called a wandering or migrating leiomyoma [1]. Occasionally such tumors become adherent to surrounding structures such as the broad ligament or omentum, develop an auxiliary blood supply and lose their original attachment to the uterus. They are then called parasitic leiomyomas [1,2]. Rarely, a parasitic leiomyoma may become torsive and cause an acute abdomen [3]. Pedunculated leiomyomas of the uterus are not uncommon.

\section{Case Report}

45 year old women presented to outpatient clinic with the complaint of abdominal distention for last 6 months. Her menstrual cycle was normal ranging from 28-30 days with 3 days of moderate bleeding not associated with pain. She was P2L2 with first normal vaginal delivery and second cesarean section for fetal distress. Patient was hypertensive and was on amlodipine $2.5 \mathrm{mg}$ once daily on which her blood pressure was maintained. On examination, her general condition was fair, build and nutrition average, temperature normal, pulse 72 bpm, regular and BP 120/80 $\mathrm{mmHg}$. Her cardiovascular, central nervous system and respiratory system examination was unremarkable.

She had nontender, transverse abdominal scar of previous cesarean section. A mass was felt in

Corresponding Author: Dr. Anandita

Email: ananditasidhu@gmail.com

Received: April 30, 2015 | Accepted: August 24, 2015 | Published Online: September 10, 2015

This is an Open Access article distributed under the terms of the Creative Commons Attribution License (creativecommons.org/licenses/by/3.0)

Conflict of interest: None declared | Source of funding: Nil | DOl: http://dx.doi.org/10.17659/01.2015.0099 
left upper quadrant. On per speculum examination, cervix and vagina were healthy with no discharge. On per vaginum examination, retroverted bulky uterus was felt separately from the mass, with both fornices free. The patient brought with her FNAC report of the mass, ultrasound (USG) and CECT done from some diagnostic center. Her fine needle aspiration report gave impression of benign mesenchymal lesion with no atypia.

USG whole abdomen report showed anteverted uterus of size $96 \times 66 \times 54 \mathrm{~mm}$ with endometrial thickness of $5 \mathrm{~mm}$; and lobulated solid mass of $110 \times 71 \times 71 \mathrm{~mm}$ in left paravertebral region and normal ovaries. CECT report of whole abdomen showed well defined multilobulated soft tissue mass in left lower quadrant closely abutting uterine fundus and left ovary. Right ovary was visualized separately. Impression was ?exophytic uterine leiomyoma or mesenchymal lesion. The per-operative findings of laparotomy were a mass in the left peritoneal cavity measuring $11 \times 9 \mathrm{~cm}$ and bulky uterus. There were no adhesions and bilateral adnexa were normal. Histopathology was suggestive of interlacing and whorled bundle of smooth muscle cells with no atypia or malignancy [Fig. 1,2]. Impression was leiomyoma.

\section{Discussion}

Leiomyomas are the commonest benign tumors of the uterus. Depending upon their location, they are labelled as intramural (when in the walls of the uterus), subserosal (when beneath the serous coat) and submucosal (when beneath the mucosa and may be protruding into the uterine cavity). Submucosal leiomyomas increase the bleeding surface and may result in menorrhagia or metromenorrhagia along with pain and they may also become pedunculated.

These pedunculated fibroids develop when a subserous fibroid grows a pedicle (stalk) and as they grow larger, may become twisted and cause

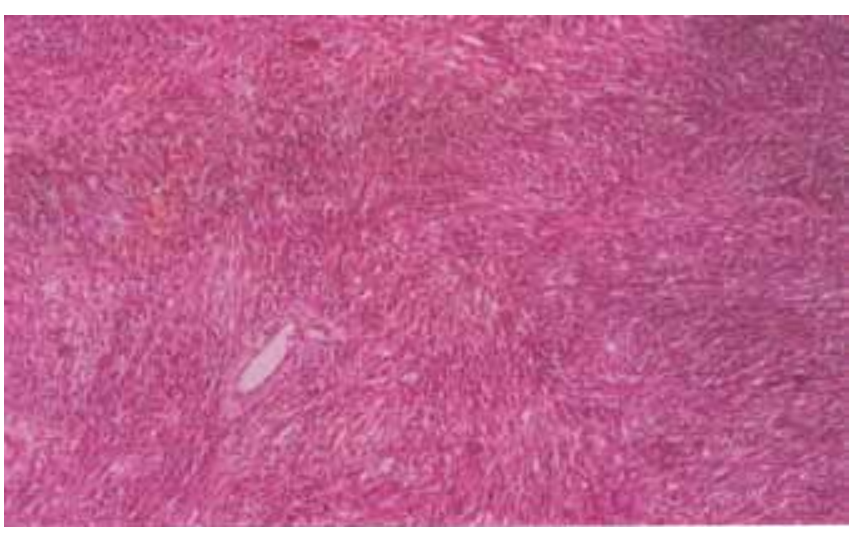

Fig.1: Interlacing and whorled bundle of smooth cells.

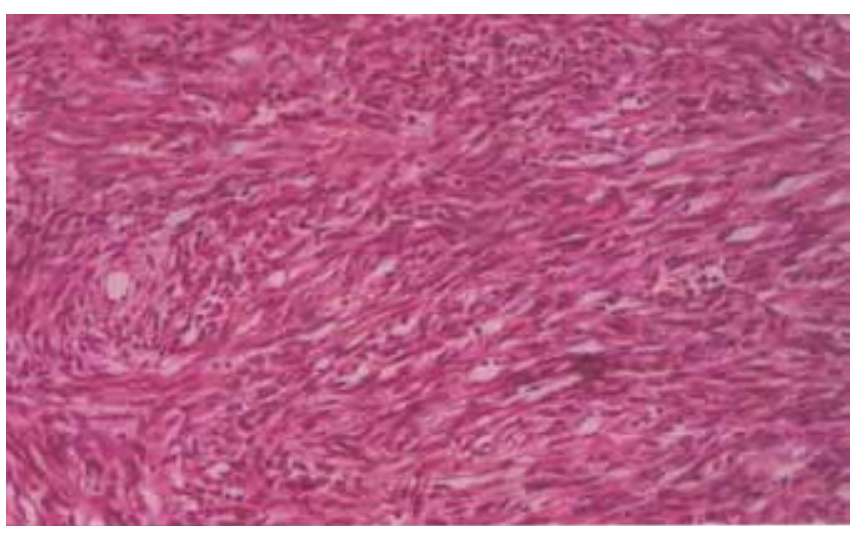

Fig.2: Magnified view of Fig.1.

severe pain. Since pedunculated parasitic fibroids are separate from the uterus, they are easily mistaken for the adnexal masses. If a pelvic mass is palpable separate from the uterus and ovaries then ultrasound diagnoses of pedunculated leiomyoma can be established. Pedunculated leiomyomas of the uterus are not uncommon. However, parasitic leiomyomas of the uterus have been described only rarely in the ultrasonographic literature [3-5].

If uterus and leiomyoma are deep into the pelvis, endovaginal ultrasonography should be performed. The transducer is placed in between the two structures and pressure is applied with the transducer to push the two structures apart. 
A pedicle connecting the two structures often can be demonstrated easily by this method. If the two structures are high in the pelvis (e.g, leiomyoma is adjacent to the fundus of an enlarged uterus), endovaginal scanning may not visualize the area well. In such instances, a trans-abdominal approach is necessary. These two structures can be pushed apart through the anterior abdominal wall with the transducer to demonstrate the pedicle. Demonstration of the vessels connecting the leiomyoma to the uterus on colour Doppler ultrasongraphy will further confirm the diagnosis of pedunculated leiomyoma.

If a pedicle is not visualized, a pedunculated leiomyomas still should be considered, since the pedicle may too thin to be seen by ultrasonography. A parasitic leiomyoma should also be considered in the differential diagnosis. In elective cases, diagnostic laparoscopic examination of abdomen can also be done to further confirm the diagnosis before laparotomy.

The present patient was from rural area, admitted with pain abdomen and history of previous LSCS. She brought with her FNAC report of the mass. USG and CECT done at some diagnostic centre with the impression of some mesenchymal lesion with no atypia. CECT showed well defined multilobulated soft tissue in the left lower quadrant abutting uterine fundus and left ovary. Impression was ?exophytic uterine leiomyoma. Histopathology of excised mass was suggestive of leiomyoma.

\section{References}

1. Robbins SL, Cotran RS, Kumar V. Pathologic Basis of Disease. $3^{\text {rd }}$ ed. W. B. Saunders, Philadelphia, pp. 1109.

2. Ritchie AC. Boyd's Textbook of Pathology. $9^{\text {th }}$ Ed. Vol.Il. Philadelphia, Lea \& Febger, 1980 pp. 1352.

3. Broody S, Brooky NY. Parasitic fibroid. Am J Obstet Gynaecol. 1953;65:1354.

4. Brieger GM, MacGibbon Al, Peat BP. Torsion of parasitic fibroid. Aust N Z J Obstet Gyaecol. 1995;35:224.

5. Gowri V, Sudherndra A Oumachigul A, Sankaran V. Giant broad ligament leiomyoma. Int J Gynaecol Obstet. 1992;37:207-210.

6. Baltarowich $\mathrm{OH}$ Kurtz $A B$, Pernell RG, Needleman. Pitfalls in the sonographic diagnosis of uterine fibroids. AJR. 1988;151:725. 